\title{
Stapled versus hand-sewn intestinal anastomosis in pediatric patients: a systematic review and meta-analysis
}

\author{
Takayuki Fujii* (1), Aya Tanaka, Hiroto Katami and Ryuichi Shimono
}

\begin{abstract}
Background: The safety and feasibility of stapled intestinal anastomosis have been widely reported in adults. However, the efficacy of stapled anastomosis (SA) in children is unclear. The aim of this study was to perform a systematic review and meta-analysis to evaluate the safety and effectiveness of SA compared with hand-sewn anastomosis (HA) in pediatric patients.

Methods: A systematic literature search was performed using PubMed, the Cochrane Library, and Scopus databases. Studies comparing outcomes of children aged $<7$ years and subgroups of children aged $<1$ year who underwent SA or HA were included. Primary outcomes were anastomotic leakage and anastomotic stricture. Mean differences (MDs) with $95 \%$ confidence intervals (Cls) were calculated for continuous variables. Odds ratios (ORs) with $95 \% \mathrm{Cls}$ were calculated for dichotomous variables. Interstudy heterogeneity was assessed using the chi-squared test and was quantified using the $I^{2}$ statistic.

Results: One randomized control trial and five retrospective cohort studies, comprising 633 cases (229 SA cases and $404 \mathrm{HA}$ cases), were included. No significant differences were observed in anastomotic leakage (6.5\% vs. 7.4\%; $\mathrm{OR}, 0.93 ; 95 \% \mathrm{Cl}, 0.37-2.34 ; p=0.88$ ), anastomotic stricture (4.1\% vs. $9.3 \%$; OR, $0.54 ; 95 \% \mathrm{Cl}, 0.19-1.51 ; p=0.24$ ), ileus (7.1\% vs. $9.3 \%, \mathrm{OR}, 2.35 ; 95 \% \mathrm{Cl}, 0.15-37.51 ; p=0.54$ ), anastomosis-related complications ( $9.5 \%$ vs. $10.9 \%$, OR, 0.98 ; $\left.95 \% \mathrm{Cl}, 0.52-1.86 ; \mathrm{p}=0.96 ; \mathrm{l}^{2}=39 \%\right)$, and time until full-feeding ( $\mathrm{MD}=-3.57$ days; $95 \% \mathrm{Cl},-11.36$ to $\left.4.23 ; p=0.37\right)$ between $\mathrm{SA}$ and HA. Operative time was significantly shorter in SA than in HA in children aged $<1$ year (MD $=$ -20.36 min; $95 \% \mathrm{Cl},-26.13$ to -14.59$)$.
\end{abstract}

Conclusions: SA required shorter operative time and was comparable to HA in the overall complication rate. Although the evidence was insufficient, SA could be an option for intestinal anastomosis in children.

Keywords: Functional end-to-end anastomosis, Stapled intestinal anastomosis, Neonates, Infants, Children

*Correspondence: fujii.takayuki@kagawa-u.ac.jp

Department of Pediatric Surgery, Faculty of Medicine, Kagawa University,

1750-1, Ikenobe, Mikicho, 761-0793 Kitagun, Kagawa, Japan

(c) The Author(s) 2021. Open Access This article is licensed under a Creative Commons Attribution 4.0 International License, which permits use, sharing, adaptation, distribution and reproduction in any medium or format, as long as you give appropriate credit to the original author(s) and the source, provide a link to the Creative Commons licence, and indicate if changes were made. The images or other third party material in this article are included in the article's Creative Commons licence, unless indicated otherwise in a credit line to the material. If material is not included in the article's Creative Commons licence and your intended use is not permitted by statutory regulation or exceeds the permitted use, you will need to obtain permission directly from the copyright holder. To view a copy of this licence, visit http://creativecommons.org/licenses/by/4.0/. The Creative Commons Public Domain Dedication waiver (http://creativeco $\mathrm{mmons}$.org/publicdomain/zero/1.0/) applies to the data made available in this article, unless otherwise stated in a credit line to the data. 


\section{Background}

In pediatric surgery, intestinal anastomosis is performed in patients of various ages, conditions, and etiologies such as necrotizing enterocolitis or duodenal atresia (in infants) and Crohn's disease or malignant lymphoma (in adolescents). A safe and an effective intestinal anastomotic procedure that does not cause complications, including anastomotic leakage, anastomotic stricture, and intestinal obstruction, is required for the rapid recovery of patients.

In adults, stapled anastomosis (SA) is widely used for intestinal anastomosis. A Cochrane review reported that fewer anastomotic leakages are observed with SA than with hand-sewn anastomosis (HA) [1]. This is probably due to less inflammation of the anastomotic site [2], decreased spillage of bowel content during surgery [3], and a uniform method of anastomosis using a stapler [1].

Traditionally, end-to-end HA has been widely used for pediatric patients. Since Powell reported the usefulness of SA in infants younger than 5 months in 1995 [4], reports of SA in pediatric patients have gradually increased [5-12]. These studies reported that SA had the same frequency of complications as HA had [5-11], and SA had a shorter operative time $[5,6,10,11]$, an earlier time until initial feeding $[9,10]$, and a shorter length of hospital stay than had HA [10]. However, the number of cases in these studies was small, and the effectiveness of SA has not yet been confirmed. Therefore, the aim of this study was to perform a meta-analysis to evaluate the safety and effectiveness of SA compared with HA in pediatric patients.

\section{Methods}

\section{Protocol registration}

This meta-analysis was conducted according to the Preferred Reporting Items for Systematic Reviews and Metaanalyses (PRISMA) guidelines [13]. The protocol was registered in the International Prospective Register of Systematic Reviews (PROSPERO, registration number: CRD42021247302).

\section{Inclusion and exclusion criteria}

Pediatric patients who underwent SA or HA were included. SA was defined as a side-to-side and functional end-to-end anastomosis using any kind of stapling device. HA was defined as an end-to-end anastomosis without using a stapling device. The inclusion criteria were as follows: (1) studies comparing SA and HA, (2) pediatric patients aged $<7$ years (to investigate the efficacy and safety of SA in pre-school children), and (3) availability of at least one measurable outcome. Exclusion criteria were: (1) studies in which anastomosis was performed laparoscopically; (2) the article type was an animal study, review, letter, or case report; and (3) duplicate publication or studies that used the same patient group in both studies (in such instances, we chose the most recent study).

\section{Search strategy}

A systematic literature search was performed using PubMed, the Cochrane Library, and Scopus databases for all studies published until May 10, 2021. We placed no limitations on the language of the publication. The following search terms were used: (child* OR pediatric OR paediatric OR infant OR neonate) AND (stapled) AND (anastomo*). The reference lists of the included studies were also reviewed. The search strategy was confirmed by the clinical research expertise of the Clinical Research Support Center at Kagawa University Hospital.

\section{Data extraction}

Data on the characteristics of the study (study design, first author, country and year of publication, sample size, and follow-up period), patients (etiology, age, sex, body weight), anastomosis procedure (the modalities and suturing techniques for anastomosis), and clinical outcomes were extracted. The primary outcomes were anastomotic leakage and anastomotic stricture. The secondary outcomes were operative time, blood loss, postoperative complications (wound infection, abdominal abscess, ileus, and anastomosis related complications requiring reoperation), time until initial feeding, time until full feeding, and length of hospital stay. When there were insufficient data from the published study, we attempted to contact the authors. Data including abstracts or full texts of all potentially relevant studies were independently extracted and evaluated by two independent reviewers (TF and AT).

\section{Analysis of subgroups}

When we obtained at least two studies that sufficiently reported outcomes by subgroups, we conducted a subgroup analysis for patients aged $<1$ year.

\section{Quality assessment}

The quality of the included randomized controlled trials (RCTs) was evaluated based on the Cochrane riskof-bias tool for randomized trials (RoB 2) [14]. The quality of the included non-randomized studies of interventions was evaluated based on the risk of bias in non-randomized studies of interventions (ROBINS-I) tool [15]. Any disagreements were resolved by discussion between the two reviewers or discussion with a third reviewer (RS). 


\section{Statistical analysis}

Statistical analysis was performed using Review Manager 5.4 software (Cochrane Collaboration, Oxford, UK). Mean differences (MDs) with 95\% confidence intervals (CIs) were calculated for continuous variables. When the means and standard deviations (SDs) were not available, data for medians and interquartile ranges were extracted and converted to means and SDs using the well-established method reported by Wan et al. [16]. Odds ratios (ORs) with $95 \%$ CIs were calculated for dichotomous variables. The MDs and ORs were considered statistically significant when the $p$-value was $<0.05$. Interstudy heterogeneity was assessed using the chi-squared test and was quantified using the $I^{2}$ statistic. If the $I^{2}$ value was less than $50 \%$, a fixed-effects model was applied; otherwise, a random-effects model was applied.

\section{Results}

\section{Study characteristics}

A total of 522 studies were identified during the initial search (Fig. 1). After title and abstract screening, 15 studies remained. After full-text article screening, nine studies were excluded for the following reasons: included adults $(n=6)$, included pediatric patients older than 7 years $(\mathrm{n}=1)$, non-comparative study $(\mathrm{n}=1)$, and anastomosis underwent laparoscopically $(\mathrm{n}=1)$. Finally, six studies were included in the meta-analysis [5-10].

Table 1 shows the characteristics of the included studies. The studies included one RCT and five retrospective cohort studies totaling 633 cases: 229 SA cases and 404 HA cases. Except for the RCT study, all cohort studies performed HA when the stapling device was difficult to insert into the intestinal lumen [5-9]. Consequently, patients with HA were significantly younger and had a lighter body weight than those with SA in three studies $[5,7,9]$. Table 2 shows the modalities and suturing techniques used for the anastomoses.

\section{Risk of bias of included studies}

Table 3 shows the risk of bias assessment of the included RCTs [10]. There was some concern about bias arising from the randomization process because randomization was performed by allotting patients to each group alternately. In addition, there was some concern about bias arising from the measurement of the outcome because the blinding of outcome assessors was unclear.

Table 4 shows the risk of bias assessment in the included cohort studies [5-9]. All studies had a serious risk of bias

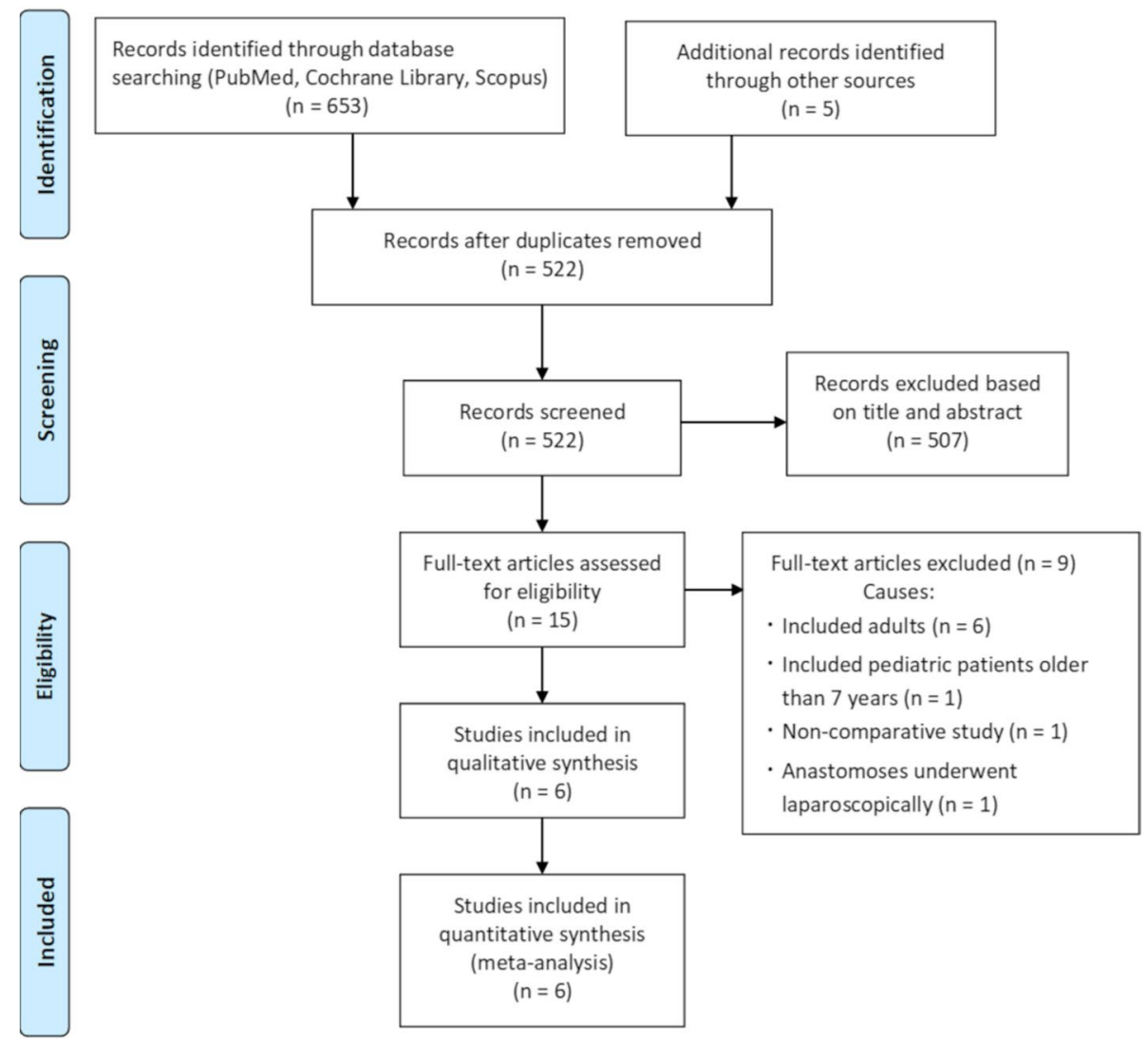

Fig. 1 PRISMA flow diagram of this meta-analysis 


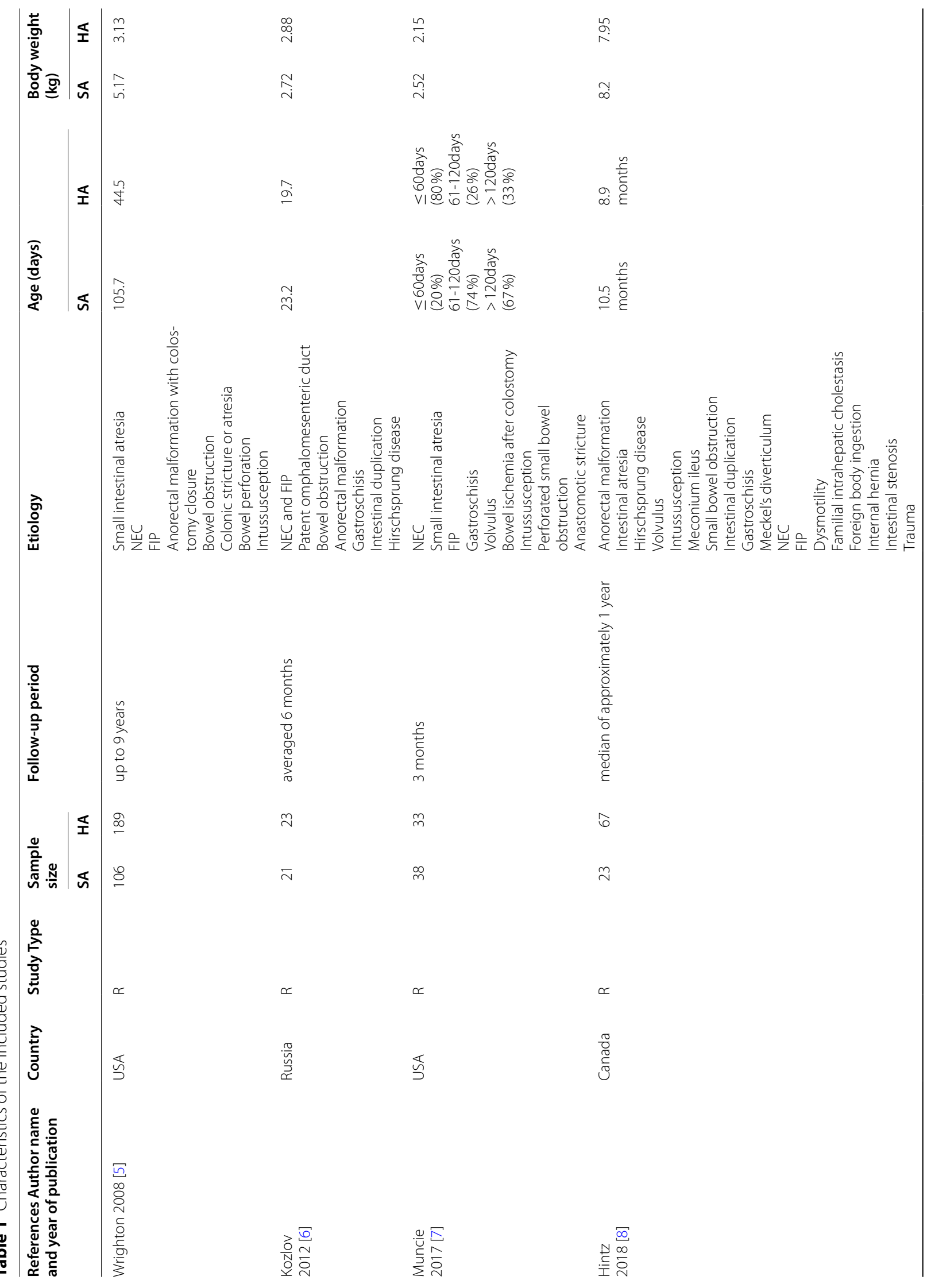




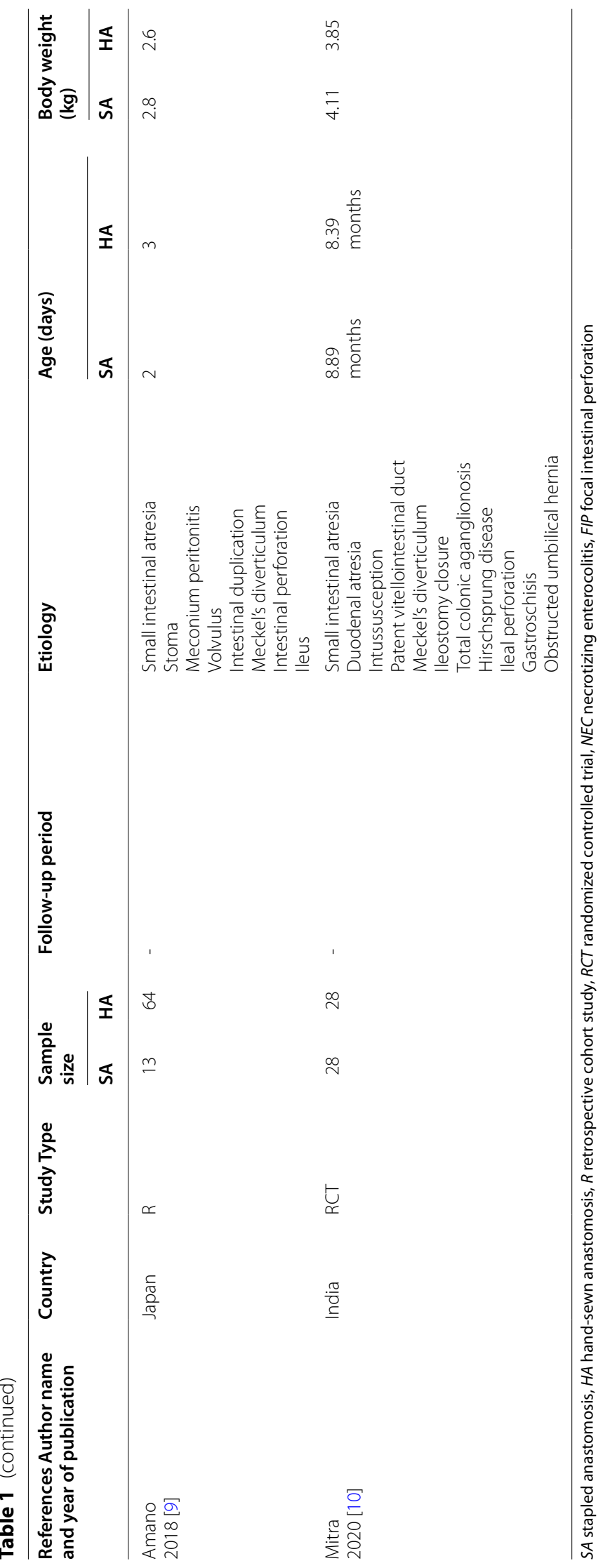


Table 2 Modalities and suturing techniques for anastomoses

\begin{tabular}{|c|c|c|c|}
\hline References & Stapled anastomosis & Hand-sewn anastomosis & \\
\hline & Stapling devices & Suture materials & Suturing techniques \\
\hline Wrighton [5] & $\begin{array}{l}\text { Endo-GIA or GIA linear cutter with 2.5-mm staples } \\
\text { (Ethicon Endo-Surgery, Cincinnati, OH, USA) }\end{array}$ & $\begin{array}{l}\text { monofilament or braided, absorbable suture mate- } \\
\text { rial }\end{array}$ & - \\
\hline Kozlov [6] & $\begin{array}{l}\text { Endopath ATW-35 Endoscopic Articulating Linear } \\
\text { Stapler with 2.5-mm staples (Ethicon Endo-Surgery, } \\
\text { Cincinnati, OH, USA) }\end{array}$ & absorbable suture material & two-layer of continuous \\
\hline Muncie [7] & $\begin{array}{l}30 \mathrm{~mm} \times 2.5 \mathrm{~mm} \text { endoscopic staplers (Covidien, } \\
\text { Mansfield, MA) }\end{array}$ & $5-0$ silk & single layer of interrupted \\
\hline Hintz [8] & $\begin{array}{l}\text { Proximate, ETS (Ethicon,Somerville, NJ), DST GIA , and } \\
\text { Endo GIA (Covidien New Haven, CT) }\end{array}$ & $\begin{array}{l}\text { monofilament or braided, absorbable suture mate- } \\
\text { rial (PDS or Vicryl) }\end{array}$ & - \\
\hline Amano [9] & $\begin{array}{l}\text { Endocutter ETS 35, ETS Flex } 45 \text { stapler, and the } \\
\text { Echelon Flex Powered ENDOPATH Stapler with 2.5- } \\
\text { or 3.5-mm staples (Johnson \& Johnson K.K., Tokyo, } \\
\text { Japan) }\end{array}$ & absorbable suture material & - \\
\hline Mitra [10] & 55 mm linear cutting Gl stapler & delayed absorbable suture material & single-layer or double-layer \\
\hline
\end{tabular}

regarding confounding factors because they included various etiologies, their influence on operative time, and the postoperative outcome cannot be ignored [5-9]. Three studies had a moderate risk of bias in selection of patients because the type of anastomosis performed was determined based on the surgeon's preference $[6,8,9]$. Another two studies had a serious risk of bias in patient selection $[5,7]$. This was because in addition to the decision of anastomosis fashion being determined based upon the surgeon preference, children in the HA group had lower body weight and were younger than those in the SA group, although this was a technical problem [5, 7]. All studies also had a moderate risk of bias in the measurement of outcomes because they were nonblinded studies [5-9].

\section{Primary outcomes (anastomotic leakage and anastomotic stricture)}

The overall rate of anastomotic leakage was not significantly different between the SA and HA groups $(6.5 \%$ vs. $7.4 \%$, OR, $0.93 ; 95 \% \mathrm{CI}, 0.37-2.34 ; \mathrm{p}=0.88 ; I^{2}=0 \%$ ) (Fig. 2a) [7-10]. In the subgroup analysis of patients aged $<1$ year, the overall rate of anastomotic leakage showed no significant difference between SA and HA groups $(7.1 \%$ vs. $7.7 \%$, OR, 0.95 ; $95 \% \mathrm{CI}, 0.34-2.68$; $\left.\mathrm{p}=0.92 ; I^{2}=0 \%\right)$ (Fig. 2b) [8-10].

Similarly, the overall rate of anastomotic stricture showed no significant difference between the SA and
HA groups $(4.1 \%$ vs. $9.3 \%$, OR, 0.54; $95 \%$ CI, 0.19 $1.51 ; \mathrm{p}=0.24 ; I^{2}=14 \%$ ) (Fig. 2c) [7-9]. In the subgroup analysis of patients aged $<1$ year, the overall rate of anastomotic stricture showed no significant difference between the SA and HA groups $(4.7 \%$ vs. $8.8 \%$, OR, $0.75 ; 95 \% \mathrm{CI}, 0.23-2.42 ; \mathrm{p}=0.63 ; I^{2}=11 \%$ ) (Fig. 2d) $[8,9]$.

\section{Secondary outcomes}

All patients who were assessed for the secondary outcomes were aged $<1$ year, with no patients aged $\geq 1$ year. Therefore, subgroup analysis was performed for only patients aged $<1$ year.

\section{Ileus}

Because heterogeneity was observed $\left(\mathrm{chi}^{2}=2.8 ; \mathrm{p}=0.09\right.$; $I^{2}=64 \%$ ), a random-effects model was applied. The overall rate of ileus was not significantly different between the SA and HA groups (7.1\% vs. $9.3 \%$, OR, $2.35 ; 95 \% \mathrm{CI}$, $0.15-37.51 ; p=0.54$ ) (Fig. 3a) [8, 9].

\section{Anastomosis related complications requiring reoperation}

The overall rate of anastomosis related complications showed no significant difference between the SA and HA groups $(9.5 \%$ vs. $10.9 \%$, OR, 0.98 ; $95 \%$ CI, 0.52-1.86; $\left.\mathrm{p}=0.96 ; I^{2}=39 \%\right)($ Fig. 3b) $[5,9,10]$.

Table 3 Risk of bias assessment of the included randomized controlled trials (ROB 2)

\begin{tabular}{|c|c|c|c|c|c|c|}
\hline References & $\begin{array}{l}\text { Bias arising from } \\
\text { the randomization } \\
\text { process }\end{array}$ & $\begin{array}{l}\text { Bias due to } \\
\text { deviations } \\
\text { from intended } \\
\text { interventions }\end{array}$ & $\begin{array}{l}\text { Bias due to } \\
\text { Missing outcome } \\
\text { data }\end{array}$ & $\begin{array}{l}\text { Bias in measurement } \\
\text { of the outcome }\end{array}$ & $\begin{array}{l}\text { Bias in selection of } \\
\text { the reported } \\
\text { result }\end{array}$ & Overall Bias \\
\hline Mitra [10] & Some concerns & Low & Low & Some concerns & Low & Some concerns \\
\hline
\end{tabular}


Table 4 Risk of bias assessment of the included cohort studies (ROBINS-I)

\begin{tabular}{|c|c|c|c|c|c|c|c|c|}
\hline References & $\begin{array}{l}\text { Bias due } \\
\text { to confounding }\end{array}$ & $\begin{array}{l}\text { Bias in } \\
\text { selection of } \\
\text { participants } \\
\text { into the study }\end{array}$ & $\begin{array}{l}\text { Bias in } \\
\text { classification } \\
\text { of } \\
\text { interventions }\end{array}$ & $\begin{array}{l}\text { Bias due } \\
\text { to deviations } \\
\text { from intended } \\
\text { interventions }\end{array}$ & $\begin{array}{l}\text { Bias due } \\
\text { to missing } \\
\text { data }\end{array}$ & $\begin{array}{l}\text { Bias in } \\
\text { measurement } \\
\text { of outcomes }\end{array}$ & $\begin{array}{l}\text { Bias in } \\
\text { selection of the } \\
\text { reported result }\end{array}$ & Overall Bias \\
\hline Wrighton [5] & Serious & Serious & Low & Low & Low & Moderate & Low & Serious \\
\hline Kozlov [6] & Serious & Moderate & Low & Low & Low & Moderate & Low & Serious \\
\hline Muncie [7] & Serious & Serious & Low & Low & Low & Moderate & Low & Serious \\
\hline Hintz [8] & Serious & Moderate & Low & Low & Low & Moderate & Low & Serious \\
\hline Amano [9] & Serious & Moderate & Low & Low & Low & Moderate & Low & Serious \\
\hline
\end{tabular}

\section{Operative time}

Operative time was significantly shorter in the SA group than in the HA group ( $\mathrm{MD}=--20.36 \mathrm{~min} ; 95 \% \mathrm{CI}$, -26.13 to $-14.59 ; \mathrm{p}<0.001 ; I^{2}=0 \%$ ) (Fig. 3c) $[6,9]$.

\section{Time until full-feeding}

Because heterogeneity was observed $\left(\mathrm{chi}^{2}=7.8\right.$; $\mathrm{p}=0.005 ; I^{2}=87 \%$ ), a random-effects model was applied. There was no significant difference in the time until fullfeeding between the SA and HA groups (MD $=-3.57$ days; $95 \% \mathrm{CI},-11.36$ to 4.23 ; $\mathrm{p}=0.37$ ) (Fig. 3d) $[6,9]$.

The review studies were not enough to evaluate the data on blood loss, wound infection, abdominal abscess, time until initial feeding, and length of hospital stay. The data for each study are listed in Table 5 .

\section{Discussion}

The results of this meta-analysis showed that SA was comparable to HA in the overall rate of anastomotic leakage, anastomotic stricture, ileus, and anastomosis related complications in children aged $<1$ year. Moreover, the operative time was significantly shorter in the SA group than in the HA group in this population.

The safety and efficacy of SA in adults has been widely reported [1, 17]. A Cochrane review including seven RCTs with 1125 patients reported that SA had a significantly lower incidence of anastomotic leakage than had HA [1]. In addition, a recent network meta-analysis including 11 trials with 1113 patients reported that SA showed a higher probability of superiority to HA in reducing the incidence of overall postoperative complications, clinical recurrences, and reoperation [17]. Therefore, the authors advocated that SA would probably be the optimal anastomosis for Crohn's disease.

There are few reports about SA in children, which may be due to concerns about the difficulty and safety of inserting the device into the narrow intestinal lumen of young children. However, with the development of minimally invasive surgeries and the compactness of stapling devices, SA can be safely performed, even in newborns and infants. In 1995,
Powell reported the usefulness of SA in a case series of seven neonates or young infants with a mean age of 72 days and a mean weight of $3.7 \mathrm{~kg}$ [4]. Subsequently, a retrospective cohort study of 44 children with a mean age of 23 days and a mean weight of $2.7 \mathrm{~kg}$ in the SA group reported that there were no intra- and postoperative complications compared to those with HA [6]. A recent RCT study of 56 children with a mean age of 8.9 months and a mean weight of $4.1 \mathrm{~kg}$ in the SA group reported that there was no difference in the number of complications between the SA and HA groups. Patients with SA had less blood loss and shorter length of hospital stay than that had those with HA [10]. In addition, a multivariate analysis revealed that both SA procedure and body weight were not independent predictors of anastomotic complications [8]. In this study, there were no significant differences in the number of anastomotic leakages, anastomotic strictures, ileus, and anastomosisrelated complications requiring surgery in children aged $<1$ year. Although there is a limit on the size of the intestinal lumen into which the stapling device can be safely inserted, SA could be acceptable even in small children. Recently, the feasibility and safety of a 5-mm stapler in small children have been reported $[18,19]$. Although the $5-\mathrm{mm}$ stapler was not used in this study, such miniature devices may offer an alternative to HA in the smaller intestinal lumen.

Many studies on SA have reported that the operative time was shorter in SA than in HA $[5,6,9,10]$. Similarly, in this study, operative time was significantly shorter in the SA group than in the HA group in children aged $<1$ year. Shorter operative times may reduce the strain on the patient and intestinal tissue and accelerate the recovery of intestinal peristalsis. In fact, in the studies of Mitra et al. and Amano et al., SA had a shorter operative time and lesser time until initial feeding than HA $[9,10]$.

There were two studies which reported specific complications associated with SA. Jackson et al. reported that children aged 5 -and 7 years had intestinal volvulus and bacterial overgrowth due to huge dilatation of the anastomotic site after SA at 2 months and 3 years of age, respectively [20]. Amano et al. reported two cases of complications [9]. One patient was a 5-year-old child 


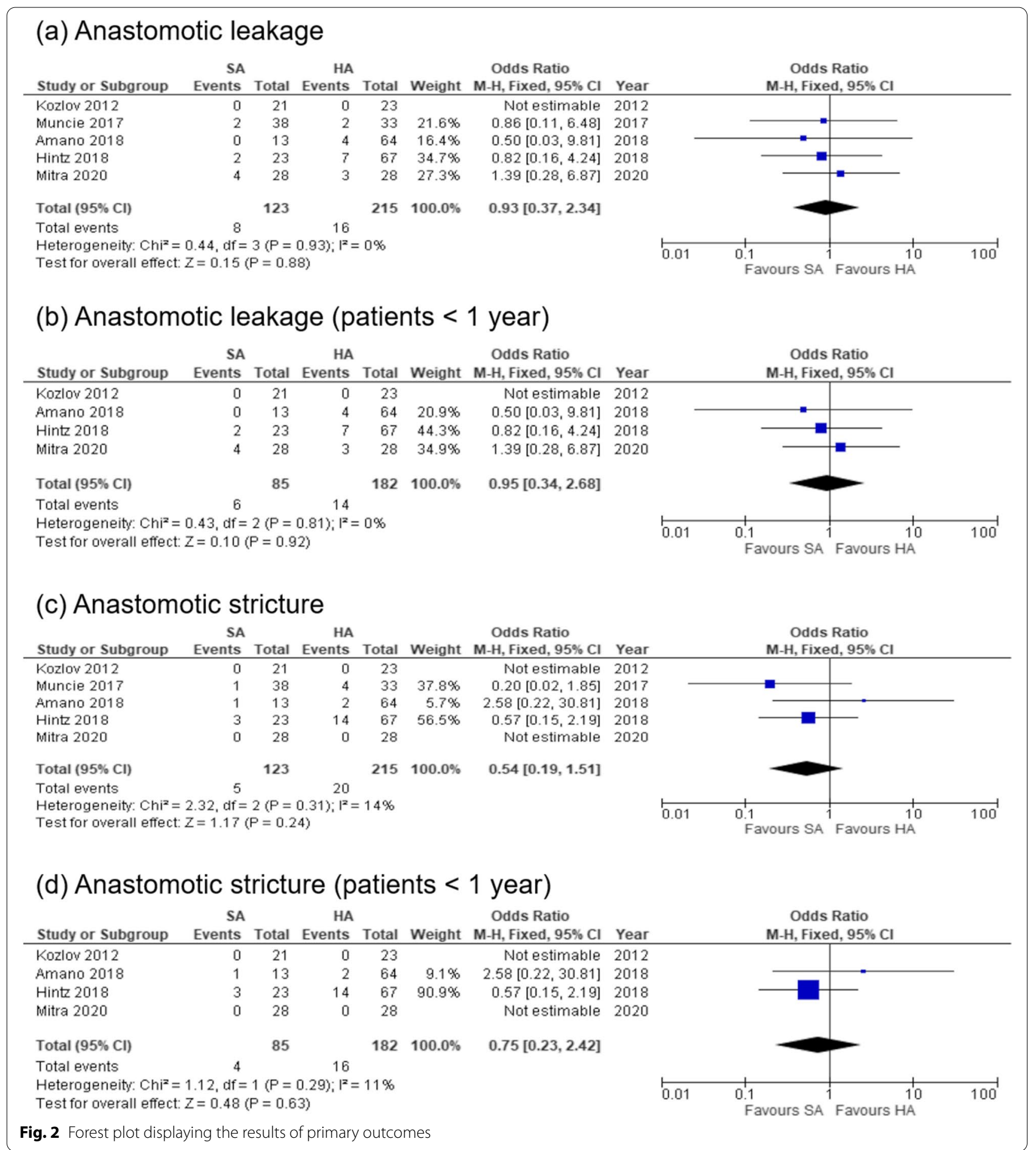

who had small intestinal volvulus, with two adhesive bands and anastomotic dilatation after SA at 1 day of age. The other case was an infant who had midgut malrotation with volvulus and anastomotic dilatation 4 months after SA for repair of intestinal atresia. Although the authors believe that the volvulus was mainly caused by malrotation and adhesive bands, it might be triggered by dilatation of the anastomotic site [9]. It should be noted that such intestinal obstruction may occur infrequently.

This study had several limitations that could affect generalization. First, the number of studies identified was limited, which may have resulted in insufficient experience to detect outcomes. Second, the available evidence had a risk of bias because the RCTs had some concerns, 


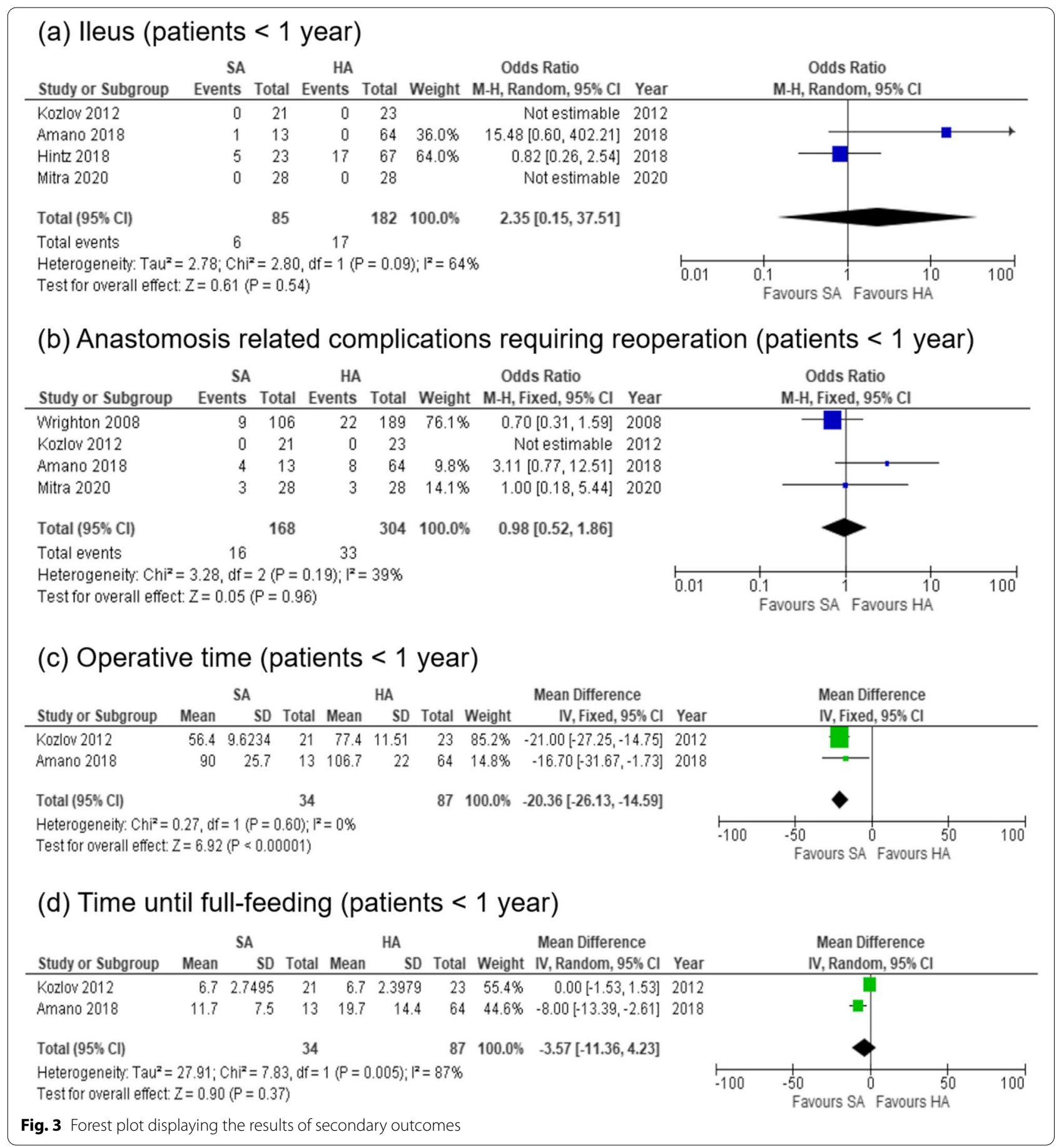

and all other cohort studies had a serious risk of bias. In particular, because all studies included various etiologies, their influence on operative time and postoperative outcome cannot be ignored. In addition, all cohort studies had a moderate or serious risk of bias in selection patients because the decision of anastomosis fashion was determined based on the surgeon's preference or a technical problem. Consequently, the HA groups tended to be smaller and younger than the SA group, which would affect the outcomes. Third, many of included studies had short or unclear follow-up periods. As a result, relatively delayed complications specific to SA, such as bleeding at the staple line [7] or intestinal obstruction, as stated above, may have been overlooked $[9,20]$. Despite these limitations, this study was the first meta-analysis to investigate the efficacy of SA in pediatric patients 
Table 5 Outcomes of the included studies

\begin{tabular}{|c|c|c|c|c|c|c|c|c|c|c|c|c|c|}
\hline \multirow[t]{2}{*}{ References } & \multicolumn{2}{|c|}{ Operative time (min) } & \multicolumn{3}{|c|}{ Estimated blood loss (ml) } & \multicolumn{2}{|c|}{$\begin{array}{l}\text { Wound } \\
\text { infection }\end{array}$} & \multicolumn{2}{|c|}{$\begin{array}{l}\text { Abdominal } \\
\text { abscess }\end{array}$} & \multicolumn{2}{|c|}{$\begin{array}{l}\text { Time to initial } \\
\text { oral feeding } \\
\text { (day) }\end{array}$} & \multicolumn{2}{|c|}{$\begin{array}{l}\text { Length of } \\
\text { stay (day) }\end{array}$} \\
\hline & SA & $\mathrm{HA}$ & & SA & $\mathrm{HA}$ & SA & $\mathrm{HA}$ & SA & $\mathrm{HA}$ & SA & HA & SA & $\mathrm{HA}$ \\
\hline Wrighton [5] & 102.5 & 128.2 & & 18.0 & 18.8 & - & - & - & - & - & - & - & - \\
\hline Kozlov [6] & $\begin{array}{l}56.4 \\
(2.1)^{\mathrm{a}}\end{array}$ & $\begin{array}{l}77.4 \\
(2.4)^{\mathrm{a}}\end{array}$ & & - & - & 0 & 0 & 0 & 0 & - & - & $\begin{array}{l}14.1 \\
(1.5)^{\mathrm{a}}\end{array}$ & $\begin{array}{l}13.3 \\
(1.0)^{\mathrm{a}}\end{array}$ \\
\hline Muncie [7] & - & - & & - & - & - & - & - & - & - & - & - & - \\
\hline Hintz [8] & $127^{b}$ & $107^{b}$ & $\begin{array}{l}<10 \mathrm{~mL} \\
10-100 \mathrm{~mL} \\
>100 \mathrm{~mL}\end{array}$ & $\begin{array}{l}34.8 \% \\
52 \% \\
4.3 \%\end{array}$ & $\begin{array}{l}55.2 \% \\
31.3 \% \\
1.5 \%\end{array}$ & - & - & 0 & 0 & $7^{b}$ & $3^{b}$ & $11^{b}$ & $7^{b}$ \\
\hline Amano [9] & $\begin{array}{l}85^{c} \\
(77-108)\end{array}$ & $\begin{array}{l}109^{c} \\
(91-120)\end{array}$ & & $\begin{array}{l}13^{c} \\
(8-24)\end{array}$ & $\begin{array}{l}10^{c} \\
(5-25)\end{array}$ & 0 & 0 & 0 & 0 & $\begin{array}{l}4^{c} \\
(3-7)\end{array}$ & $\begin{array}{l}7^{c} \\
(5-10)\end{array}$ & - & - \\
\hline Mitra [10] & 23.9 & 33.1 & & 22.7 & 27.8 & 2 & 5 & - & - & 5.4 & 7 & 6.7 & 8.7 \\
\hline
\end{tabular}

SA stapled anastomosis, HA hand-sewn anastomosis, ${ }^{a}$ mean (standard error), ${ }^{b}$ median, ${ }^{c}$ median (interquartile range)

and showed that SA could be comparable to HA. To strengthen our understanding and resolve the problems we faced, a prospective well-designed RCT with a larger number of subjects should be performed.

\section{Conclusions}

In this study, SA had the advantage of a shorter operative time than had HA in children aged $<1$ year. SA was comparable to HA in the overall rate of anastomotic leakage, anastomotic stricture, ileus, and anastomosis-related complications. Although the evidence was insufficient, SA could be an option for intestinal anastomosis in a variety of etiologies when inserting the stapling device into the intestinal lumen, even in neonates or infants.

\section{Abbreviations}

SA: Stapled anastomosis; HA: Hand-sewn anastomosis; RCT: Randomized controlled trial; MD: Mean difference; Cl: Confidence interval; SD: Standard deviation; OR: Odds ratio.

\section{Acknowledgements}

The authors thank Dr. Jun Kunikata for his useful advice for systematic literature search. The authors acknowledge all the authors the original studies included in this study.

\section{Authors' contributions}

All authors contributed to the conception and design of the study. Literature search, data collection, and analysis were performed by TF, AT, and RS. The first draft of the manuscript was written by TF and RS, and all authors commented on the previous versions of the manuscript. All authors read and approved the final manuscript.

\section{Funding}

This work was supported by JSPS KAKENHI Grant Number JP 20K17555. The funders had no role in the design, data collection, analysis of neither the study, nor the decision to publish or the preparation of this manuscript.

\section{Availability of data and materials}

All data analysed during this study are included in this published article.

\section{Declarations}

Ethics approval and consent to participate

Not applicable.

\section{Conflict of interest}

The authors declare that they have no competing interests.

\section{Consent for publication}

Not applicable.

Received: 1 August 2021 Accepted: 23 September 2021

Published online: 06 October 2021

\section{References}

1. Choy PY, Bissett IP, Docherty JG, Parry BR, Merrie A, Fitzgerald A. Stapled versus handsewn methods for ileocolic anastomoses. Cochrane Database Syst Rev. 2011. https://doi.org/10.1002/14651858.CD004320.pub3.

2. Graffner $H$, Andersson $L$, Löwenhielm $P$, Walther $B$. The healing process of anastomoses of the colon. A comparative study using single, doublelayer or stapled anastomosis. Dis Colon Rectum. 1984;27:767-71. doi:https://doi.org/10.1007/BF02553934.

3. Kracht M, Hay JM, Fagniez PL, Fingerhut A. Ileocolonic anastomosis after right hemicolectomy for carcinoma: Stapled or hand-sewn? A prospective, multicenter, randomized trial. Int J Colorectal Dis. 1993;8:29-33. doi:https://doi.org/10.1007/BF00341273.

4. Powell RW. Stapled intestinal anastomosis in neonates and infants: Use of the endoscopic intestinal stapler. J Pediatr Surg. 1995;30:195-7. doi:https://doi.org/10.1016/0022-3468(95)90559-6.

5. Wrighton L, Curtis JL, Gollin G. Stapled intestinal anastomoses in infants. J Pediatr Surg. 2008;43:2231-4. doi:https://doi.org/10.1016/j.jpedsurg.2008. 08.052.

6. Kozlov Y, Novogilov V, Podkamenev A, Weber I. Stapled bowel anastomoses in newborn surgery. Eur J Pediatr Surg. 2013;23:63-6. doi:https://doi. org/10.1055/s-0032-1326952.

7. Muncie C, Morris M, Berch B, Sawaya D, Blewett C. Stapled intestinal anastomoses with endoscopic staplers in premature infants. J Pediatr Surg. 2017;53:126-9. doi:https://doi.org/10.1016/j.jpedsurg.2017.10.024.

8. Hintz GC, Alshehri A, Bell CM, Butterworth SA. Stapled versus hand-sewn pediatric intestinal anastomoses: A retrospective cohort study. J Pediatr Surg. 2018;53:959-63. doi:https://doi.org/10.1016/j.jpedsurg.2018.02.021.

9. Amano H, Tanaka Y, Tainaka T, Hinoki A, Kawashima H, Kakihara T, et al. The impact of body weight on stapled anastomosis in pediatric patients. 
J Pediatr Surg. 2018;53:2036-40. doi:https://doi.org/10.1016/j.jpedsurg. 2018.04.030.

10. Mitra AS, Chandak U, Kulkarni KK, Nagdive N, Saoji R, Tiwari C. Stapled vs conventional hand-sewn gastrointestinal anastomosis during infancy: A prospective comparative study from central India. Euroasian J Hepatogastroenterol. 2020;10:11-5. doi:https://doi.org/10.5005/jp-journ als-10018-1308

11. Sato K, Uchida H, Tanaka Y, Takazawa S, Jimbo T, Deie K. Stapled intestinal anastomosis is a simple and reliable method for management of intestinal caliber discrepancy in children. Pediatr Surg Int. 2012;28:893-8. doi:https://doi.org/10.1007/s00383-012-3146-y.

12. Mitchell IC, Barber R, Fischer AC, Schindel DT. Experience performing 64 consecutive stapled intestinal anastomoses in small children and infants. J Pediatr Surg. 2011;46:128-30. doi:https://doi.org/10.1016/j.jpedsurg. 2010.09.076.

13. Moher D, Liberati A, Tetzlaf J, Altman DG, PRISMA Group. Preferred reporting items for systematic reviews and meta-analyses: the PRISMA statement. Int J Surg. 2010;8:336-41. doi:https://doi.org/10.1371/journal. pmed.1000097.

14. Sterne JAC, Savović J, Page MJ, Elbers RG, Blencowe NS, Boutron I, et al. RoB 2: a revised tool for assessing risk of bias in randomised trials. BMJ. 2019:366:14898. doi:https://doi.org/10.1136/bmj.14898.

15. Sterne JAC, Hernán MA, Reeves BC, Savović J, Berkman ND, Viswanathan $M$, et al. ROBINS-I: a tool for assessing risk of bias in non-randomised studies of interventions. BMJ. 2016;355:14919. doi:https://doi.org/10.1136/bmj. i4919.

16. Wan X, Wang W, Liu J, Tong T. Estimating the sample mean and standard deviation from the sample size, median, range and/or interquartile range. BMC Med Res Methodol. 2014;14:135. doi:https://doi.org/10.1186/ 1471-2288-14-135.

17. Feng JS, Li JY, Yang Z, Chen XY, Mo JJ, Li SH. Stapled side-to-side anastomosis might be benefit in intestinal resection for Crohn's disease: A systematic review and network meta-analysis. Medicine. 2018;97:e0315. doi:https://doi.org/10.1097/MD.0000000000010315.

18. Walk CT, Meagher D, Christian J, Barnett S, Pence J, Chaudhary M, et al. Neonatal intestinal anastomosis using a $5 \mathrm{~mm}$ laparoscopic stapler. J Laparoendosc Adv Surg Tech A. 2019;29:579-81. doi:https://doi.org/10. 1089/lap.2018.0524.

19. Holler AS, Muensterer OJ, Martynov I, Gianicolo EA, Lacher M, Zimmermann P. Duodenal atresia repair using a miniature stapler compared to laparoscopic hand-sewn and open technique. J Laparoendosc Adv Surg Tech A. 2019;29:1216-22. doi:https://doi.org/10.1089/lap.2019. 0057.

20. Jackson CC, Bettolli MM, De Carli CF, Bass J, Rubin SZ, Sweeney B. Beware of stapled side-to-side bowel anastomoses in small children. Eur J Pediatr Surg. 2007;17:426-7. doi:https://doi.org/10.1055/s-2007-989268.

\section{Publisher's Note}

Springer Nature remains neutral with regard to jurisdictional claims in published maps and institutional affiliations.
Ready to submit your research? Choose BMC and benefit from:

- fast, convenient online submission

- thorough peer review by experienced researchers in your field

- rapid publication on acceptance

- support for research data, including large and complex data types

- gold Open Access which fosters wider collaboration and increased citations

- maximum visibility for your research: over $100 \mathrm{M}$ website views per year

At BMC, research is always in progress.

Learn more biomedcentral.com/submissions 